\title{
Risk scores for predicting mortality after surgical ventricular reconstruction for ischemic cardiomyopathy: Results of a Japanese multicenter study
}

\author{
Satoru Wakasa, MD, PhD, ${ }^{\text {a }}$ Yoshiro Matsui, MD, PhD, ${ }^{\text {a }}$ Tadashi Isomura, $\mathrm{MD}, \mathrm{PhD},{ }^{\mathrm{b}}$ \\ Shuichiro Takanashi, MD, PhD ${ }^{\mathrm{c}}$ Atsushi Yamaguchi, MD, PhD, ${ }^{\mathrm{d}}$ Tatsuhiko Komiya, MD, ${ }^{\mathrm{e}}$ \\ Yasunori Cho, MD, PhD, ${ }^{\mathrm{f}}$ Junjiro Kobayashi, MD, PhD, ${ }^{\mathrm{g}}$ Hitoshi Yaku, MD, PhD, ${ }^{\mathrm{h}}$ \\ Kiyokazu Kokaji, MD, PhD, ${ }^{\mathrm{i}}$ Hirokuni Arai, MD, PhD, ${ }^{\mathrm{j}}$ and Yoshiki Sawa, MD, $\mathrm{PhD}^{\mathrm{k}}$
}

\begin{abstract}
Objectives: Surgical ventricular reconstruction has been believed to be beneficial for those with ischemic cardiomyopathy. However, the effectiveness of surgical ventricular reconstruction was not proved by a large-scale trial, and no report has clearly demonstrated the exact indications and limitations of surgical ventricular reconstruction. The purpose of this study was to elucidate predictive factors of mortality after surgical ventricular reconstruction and to develop a prognostic model by calculating risk scores.
\end{abstract}

\begin{abstract}
Methods: The study subjects were 596 patients who underwent surgical ventricular reconstruction for chronic ischemic heart failure in 11 Japanese cardiovascular hospitals between 2000 and 2010. Potential predictors of postoperative mortality were assessed using the Cox proportional hazards model, and a risk score was calculated.

Results: Forty-one patients died before discharge, and 81 patients died during a mean follow-up time of 2.9 years. Four independent predictors of mortality were identified: age, Interagency Registry for Mechanically Assisted Circulatory Support profile, left ventricular ejection fraction, and severity of mitral regurgitation. Each variable was assigned a number of points proportional to its regression coefficient. A risk score was calculated using the point scores for each patient, and 3 risk groups were developed: a low-risk group (0-4 points), an intermediate-risk group (5-6 points), and a high-risk group (7-12 points). Their 3-year survivals were $93 \%$, $81 \%$, and $44 \%$, respectively (log-rank $P<.001$ ). Harrell's $C$-index of the predictive model was 0.69 .
\end{abstract}

Conclusions: A simple prognostic model was developed to predict mortality after surgical ventricular reconstruction. It can be useful in clinical practice to select treatment options for ischemic heart failure. (J Thorac Cardiovasc Surg 2014;147:1868-74)

Supplemental material is available online.

From the Department of Cardiovascular and Thoracic Surgery, ${ }^{\mathrm{a}}$ Hokkaido University Graduate School of Medicine, Sapporo, Japan; Division of Cardiovascular Surgery, ${ }^{\mathrm{b}}$ Hayama Heart Center, Hayama, Japan; Department of Cardiovascular Surgery, ${ }^{\mathrm{c}}$ Sakakibara Heart Institute, Tokyo, Japan; Department of Cardiovascular Surgery, ${ }^{\mathrm{d}}$ Saitama Medical Center, Jichi Medical University, Saitama, Japan; Department of Cardiovascular Surgery, ${ }^{\text {e }}$ Kurashiki Central Hospital, Kurashiki, Japan; Department of Cardiovascular Surgery, ${ }^{\mathrm{f}}$ Tokai University School of Medicine, Isehara, Japan; Department of Cardiovascular Surgery, ${ }^{\mathrm{g}}$ National Cerebral and Cardiovascular Center, Osaka, Japan; Department of Cardiovascular Surgery, ${ }^{\mathrm{h}}$ Kyoto Prefectural University of Medicine, Kyoto, Japan; Department of Cardiovascular Surgery, ${ }^{\mathrm{i}}$ Keio University School of Medicine, Tokyo, Japan; Department of Cardiovascular Surgery, ${ }^{\mathrm{j}}$ Tokyo Medical and Dental University Graduate School of Medicine, Tokyo, Japan; and Division of Cardiovascular Surgery, ${ }^{\mathrm{k}}$ Osaka University Graduate School of Medicine, Osaka, Japan.

Disclosures: Authors have nothing to disclose with regard to commercial support.

Received for publication Feb 21, 2013; revisions received May 2, 2013; accepted for publication June 27, 2013; available ahead of print Aug 21, 2013.

Address for reprints: Yoshiro Matsui, MD, PhD, Director of the Department of Cardiovascular and Thoracic Surgery, Hokkaido University Graduate School of Medicine, Kita-15, Nishi-7, Kita-ku, Sapporo 060-8638, Japan (E-mail: ymatsui@med.hokudai.ac.jp).

$0022-5223 / \$ 36.00$

Copyright $(\odot) 2014$ by The American Association for Thoracic Surgery

http://dx.doi.org/10.1016/j.jtcvs.2013.06.036
Indications for ischemic heart failure treatments vary depending on the severity of the patient's condition. Surgical ventricular reconstruction (SVR) has been believed to be beneficial for those with ischemic cardiomyopathy. ${ }^{1-3}$ However, the Surgical Treatment for Ischemic Heart Failure (STICH) trial concluded that SVR plus coronary artery bypass grafting $(\mathrm{CABG})$ had no further beneficial effect on survival compared with CABG alone. ${ }^{4}$ However, the STICH results are controversial because this largescale trial enrolled patients with less severe disease than in the previous studies supporting the effectiveness of SVR. ${ }^{5}$ In contrast, implantable ventricular assist devices (VADs) have become more common in the treatment of severe heart failure and are filling a gap between medical treatment and heart transplantation. ${ }^{6}$ However, VAD therapy has inherent unresolved problems, ${ }^{7,8}$ such as neurologic dysfunction, bleeding, device failure, pump thrombosis, and lower cost-effectiveness, which may not be associated with SVR. Therefore, SVR could be more beneficial for appropriately selected patients compared with CABG alone or VAD therapy. We hypothesized that risk stratification for SVR could make it possible to identify the responders to this procedure and therefore help with appropriate patient selection, which in turn would 


$\begin{array}{ll}\text { Abbreviations and Acronyms } \\ \text { CABG }= & \text { coronary artery bypass grafting } \\ \text { INTERMACS = } & \text { Interagency Registry for } \\ & \text { Mechanically Assisted Circulatory } \\ & \text { Support } \\ = & \text { left ventricle } \\ \text { LV } & \text { left ventricular ejection fraction } \\ \text { LVEF } & \text { left ventricular end-systolic } \\ \text { LVESVI } & \text { volume index } \\ & =\text { mitral regurgitation } \\ \text { MR } & =\text { New York Heart Association } \\ \text { NYHA } & \text { Surgical Treatment for Ischemic } \\ \text { STICH } & \text { Heart Failure } \\ \text { SVR } & =\text { surgical ventricular reconstruction } \\ \text { VAD } & =\text { ventricular assist device }\end{array}$

contribute to more practical comparisons among different procedures for ischemic heart failure. Therefore, the purpose of this study was to develop a practical prognostic model to predict mortality after SVR for ischemic heart failure by calculating a risk score using a multivariate Cox proportional hazards model.

\section{MATERIALS AND METHODS \\ Study Design}

We conducted a retrospective multicenter study to investigate the outcomes of SVR. Those who underwent SVR for ischemic heart failure from 2000 to 2010 in 11 Japanese cardiovascular hospitals were enrolled in this study. The indications for SVR were aneurysmal and akinetic left ventricle (LV) in 194 patients (31\%) and 412 patients (69\%), respectively. Participating hospitals were selected on the basis of the number of SVR procedures performed annually. Principally, the hospitals that performed 5 or more SVR procedures annually were selected $(n=7)$. Although 4 hospitals did not have 5 cases per year on average during the study period, they were selected because they were leading cardiovascular centers in Japan that also perform heart transplantation $(n=2)$ or because of their recent academic activities $(n=2)$. The median number of SVR procedures in each hospital during the study period was 52 (range, 17-166) cases. All data were retrospectively collected from medical records and examination reports. Mortality was detected on the basis of medical records or follow-up inquiries to the attending cardiologists that were made in each hospital. The study protocol was approved by the institutional review boards in all of the participating hospitals.

Initially, 627 patients were enrolled in this study. Then those with acute myocardial ischemia, no LV incision, and no follow-up data were excluded. Finally, there were 596 study subjects. The LV sizes and functions were measured using multiple modalities within 2 weeks before surgery. Postoperative imaging studies were repeated before discharge at $0.8 \pm 1.8$ months after surgery. Echocardiography was performed for all the patients. LV enddiastolic diameter, LV end-systolic diameter, and LV ejection fraction (LVEF) were acquired by B-mode echocardiography. The severity of mitral regurgitation (MR) was graded on the basis of color Doppler images as follows: $1+=$ mild, $2+=$ moderate, $3+=$ moderate-to-severe, and $4+=$ severe. $^{9}$ The deceleration time was acquired from the transmitral flow analysis. Systolic pulmonary artery pressure data were obtained from the catheter data or estimated using echocardiographic data. The LV end-diastolic volume index, LV end-systolic volume index (LVESVI), and LVEF were collected from the results of left ventriculograms, quantitative gated scintigrams, and magnetic resonance imaging in 288, 82, and 49 patients, respectively. For the patients with multimodality assessments, the modality that was available both preoperatively and postoperatively was selected to compare the values before and after surgery. Complete imaging data sets of preoperative and postoperative values from the same modality were acquired for LV diameters, LVEF, and LV volumes in 542 patients $(91 \%), 515$ patients $(95 \%)$, and 299 patients $(50 \%)$, respectively.

\section{Statistical Analyses}

Continuous variables were expressed as mean \pm standard deviation, and categoric variables were expressed as numbers and percentages. The percentage was calculated exclusive of those with missing values. Preoperative and postoperative data were compared using the Wilcoxon signedrank test. Intergroup comparisons for categoric data were conducted using the chi-square test or Fisher exact test, if appropriate. Postoperative mortality was estimated using the Kaplan-Meier method, and differences in mortality among groups were assessed by the log-rank test. Univariate and multivariate Cox proportional hazards models were used to determine the contributions of potential variables to the mortality. Variables for the multivariate model were selected considering the proportion of patients with missing data $(<5 \%)$, the results of univariate analyses, their confounding, and the clinical importance. Selection of variables in the multivariate analysis was performed using the backward elimination method $(P<.10)$. Finally, to develop a practical prognostic score, we assigned the independent predictors in the final Cox model weighted point scores proportional to the $\beta$ regression coefficient values (multiplied by a constant and rounded to the nearest integer). A risk score was then calculated for each patient, and the population was divided into 3 categories: patients at low risk, patients at intermediate risk, and patients at high risk for postoperative mortality. The predictive accuracy of the scoring system was examined by calculating Harrell's C-index. ${ }^{10}$ All analyses were performed using IBM SPSS Statistics (v20; IBM Corp, Somers, NY).

\section{RESULTS}

\section{Baseline Characteristics of Patients}

Table 1 shows the patients' baseline characteristics. Their mean age was $63 \pm 10$ (range, 29-87) years, and 372 (62\%) were male. In addition to the New York Heart Association (NYHA) functional class, the Interagency Registry for Mechanically Assisted Circulatory Support (INTERMACS) profile $^{11}$ at the time of surgery was used for the assessment of heart failure status. Those with NYHA functional class I/II were categorized into INTERMACS profile level 7 or more. Most of the patients $(81 \%)$ presented with NYHA functional class III/IV. Seventy-nine patients $(13 \%)$ required inotropic support preoperatively; of them, 21 patients $(4 \%)$ had INTERMACS profile 1.

\section{Surgical Procedures}

Table 2 summarizes the operative procedures. There were 5 different SVR procedures performed: end ventricular circular patch plasty, ${ }^{12}$ partial left ventriculectomy,${ }^{13}$ septal anterior ventricular exclusion, ${ }^{14}$ overlapping left ventriculoplasty, ${ }^{15}$ and linear ventriculoplasty. Each procedure was selected on the basis of the surgeons' preferences in each hospital. However, in common, an LV incision was placed at the myocardial scar lesion that was determined according to the findings of magnetic resonance imaging, 
TABLE 1. Baseline characteristics of patients

\begin{tabular}{|c|c|}
\hline $\mathrm{N}$ & 596 \\
\hline Age, y (range) & $63 \pm 10(29-87)$ \\
\hline Male sex, n $(\%)$ & $372(62 \%)$ \\
\hline \multicolumn{2}{|c|}{ No. of diseased coronary arteries, $\mathrm{n}(\%)$} \\
\hline None & $12(2 \%)$ \\
\hline 1 & $112(19 \%)$ \\
\hline 2 & $151(25 \%)$ \\
\hline 3 & $321(54 \%)$ \\
\hline \multicolumn{2}{|c|}{ Coronary artery lesion, $\mathrm{n}(\%)$} \\
\hline Left main & $76(13 \%)$ \\
\hline Anterior descending & $545(91 \%)$ \\
\hline Circumflex & $343(58 \%)$ \\
\hline Right & $341(57 \%)$ \\
\hline \multicolumn{2}{|l|}{ LV shape, $\mathrm{n}(\%)$} \\
\hline Aneurysmal & $184(31 \%)$ \\
\hline Akinetic & $412(69 \%)$ \\
\hline Renal failure, n (\%) & $97(16 \%)$ \\
\hline Dialysis, n (\%) & $26(4 \%)$ \\
\hline Atrial fibrillation, $\mathrm{n}(\%)$ & $49(8 \%)$ \\
\hline Beta-blocker use, n (\%) & $224(38 \%)$ \\
\hline \multicolumn{2}{|c|}{ NYHA functional class, $\mathrm{n}(\%)$} \\
\hline I & $22(4 \%)$ \\
\hline II & $150(25 \%)$ \\
\hline III & $267(45 \%)$ \\
\hline IV & $156(26 \%)$ \\
\hline \multicolumn{2}{|l|}{ INTERMACS profile } \\
\hline Level 1 & $21(3 \%)$ \\
\hline Level 2 & $12(2 \%)$ \\
\hline Level 3 & $46(8 \%)$ \\
\hline Level 4 & $77(13 \%)$ \\
\hline Level 5-6 & $267(45 \%)$ \\
\hline Level $\geq 7$ & $172(29 \%)$ \\
\hline Inotropic support, $\mathrm{n}(\%)$ & $79(13 \%)$ \\
\hline IABP, n (\%) & $73(12 \%)$ \\
\hline PCPS, n $(\%)$ & $3(0.5 \%)$ \\
\hline
\end{tabular}

IABP, Intra-aortic balloon pump; INTERMACS, Interagency Registry for Mechanically Assisted Circulatory Support; $L V$, left ventricle; NYHA, New York Heart Association; PCPS, percutaneous cardiopulmonary support.

echocardiography, or scintigraphy. A procedure using a patch was performed in 442 patients $(74 \%)$. Concomitant mitral valve procedures were performed in 259 patients $(42 \%)$, most of whom underwent annuloplasty. CABG was performed concomitantly in 513 patients $(86 \%)$ who had untreated coronary artery lesions.

\section{Cardiac Sizes and Functions}

Table 3 summarizes perioperative cardiac sizes and functions. LV sizes decreased and LVEF increased significantly after surgery $(P<.001$ for each parameter). MR improved postoperatively. Preoperatively, MR $3+$ or more was observed in 137 patients $(24 \%)$, and 485 patients $(93 \%)$ had MR $1+$ or less after surgery. In the analysis of the 299 patients with both preoperative and postoperative LV volume data from the same modality, the mean LVESVI
TABLE 2. Operative procedures

\begin{tabular}{lc}
\hline SVR procedures, $\mathrm{n}(\%)$ & $258(43 \%)$ \\
EVCPP & $14(2 \%)$ \\
PLV & $184(31 \%)$ \\
SAVE & $62(11 \%)$ \\
Overlapping & $78(13 \%)$ \\
Linear & $442(74 \%) / 154(26 \%)$ \\
Patch/nonpatch & $259(43 \%)$ \\
Mitral valve procedures, $\mathrm{n}(\%)$ & $251 \% 2 \%) / 8(1 \%)$ \\
Plasty/replacement & $99(17 \%)$ \\
Submitral procedures, $\mathrm{n}(\%)$ & $91(15 \%)$ \\
Papillary muscle approximation & $26(4 \%)$ \\
Papillary muscle suspension & $513(86 \%)$ \\
CABG, $\mathrm{n}(\%)$ & $2.6 \pm 1.6$ \\
No. of distal anastomoses & $75(13 \%)$ \\
Tricuspid annuloplasty, $\mathrm{n}(\%)$ & $24(4 \%)$ \\
Aortic valve replacement, $\mathrm{n}(\%)$ & $22(4 \%)$ \\
Maze procedure, $\mathrm{n}(\%)$ & $61(10 \%)$ \\
Surgical ablation for ventricular & \\
tachyarrhythmia, $\mathrm{n}(\%)$ & $44(7 \%)$ \\
ICD implant, $\mathrm{n}(\%)$ & $181 \pm 70$ \\
Cardiopulmonary bypass time, min & $101 \pm 54$ \\
Crossclamp time, min & \\
\hline$C A B G$, Coronary artery bypass grafting; $E V C P P$, endoventricular circular patch \\
plasty; ICD, implantable cardiac defibrillator; PLV, partial left ventriculectomy; \\
SAVE, septal anterior ventricular exclusion; $S V R$, surgical ventricular reconstruction.
\end{tabular}

reduction rates were $18 \%, 30 \%$, and $37 \%$ for those with baseline LVESVI $60 \mathrm{~mL} / \mathrm{m}^{2}$ or less, 60 to $90 \mathrm{~mL} / \mathrm{m}^{2}$, and greater than $90 \mathrm{~mL} / \mathrm{m}^{2}$, respectively; a reduction of $30 \%$ or more was achieved for $44 \%, 55 \%$, and $69 \%$ of them, respectively. The LVEF increased significantly for each group (LVESVI $\leq 60 \mathrm{~mL} / \mathrm{m}^{2}: 40 \%$ to $45 \%, P=.001$; LVESVI $60-90 \mathrm{~mL} / \mathrm{m}^{2}: 30 \%$ to $38 \%, P=.003$; LVESVI $>90 \mathrm{~mL} / \mathrm{m}^{2}: 22 \%$ to $\left.30 \%, P<.001\right)$.

\section{Postoperative Mortality}

During the follow-up period of $2.9 \pm 2.5$ years, $122 \mathrm{pa}$ tients $(21 \%)$ died. Among them, 12 patients $(2 \%)$ and 41 patients $(7 \%)$ died within 30 days after surgery and before discharge from the hospital, respectively. Cardiac-related death was observed in 60 patients $(10 \%), 22$ of whom died before discharge. Readmission and reoperation were required for 110 patients $(19 \%)$ and 15 patients $(3 \%)$, respectively. Reoperation for MR was performed in 6 patients, including 2 replacements. Among them, 5 had previous mitral valve repair concomitant with SVR. Four patients required an LV assist device, and 2 patients underwent heart transplantation.

\section{Assessment of Potential Predictors of Mortality}

Potential predictors of mortality were assessed using univariate and multivariate Cox proportional hazards models (Tables E1 and 4). Variables that were entered into the multivariate Cox model were as follows: age, sex, 
TABLE 3. Perioperative cardiac sizes and functions

\begin{tabular}{lccc}
\hline & Preoperative & Postoperative & $P$ value \\
\hline LVDd, mm (range) & $62 \pm 10(37-90)$ & $57 \pm 10(33-82)$ & $<.001$ \\
LVDs, mm (range) & $50 \pm 10(13-83)$ & $46 \pm 11(20-74)$ & $<.001$ \\
$\begin{array}{l}\text { LVEDVI, mL/m } \\
\quad(\text { range) }\end{array}$ & $144 \pm 51(45-358)$ & $103 \pm 36(40-308)$ & $<.001$ \\
LVESVI, mL/m & $107 \pm 47(29-286)$ & $70 \pm 33(22-236)$ & $<.001$ \\
$\quad($ range) & & & \\
LVEF, \% (range) & $27 \pm 10(5-78)$ & $35 \pm 12(4-65)$ & $<.001$ \\
$\begin{array}{l}\text { DT, msec (range)* } \\
\text { SPAP, mm Hg }\end{array}$ & $190 \pm 73(20-494)$ & $183 \pm 61(74-420)$ & .15 \\
$\quad($ range) & $36 \pm 17(7-86)$ & $34 \pm 18(4-120)$ & .08 \\
MR grade & $1.6 \pm 1.1$ & $0.6 \pm 0.6$ & $<.001$ \\
\hline
\end{tabular}

$D T$, Deceleration time; $L V D d$, left ventricular end-diastolic diameter; $L V D s$, left ventricular end-systolic diameter, $L V E D V I$, left ventricular end-diastolic volume index; $L V E F$, left ventricular ejection fraction; $L V E S V I$, left ventricular end-systolic volume index; $M R$, mitral regurgitation; $S P A P$, systolic pulmonary artery pressure. *Proportion of those with missing values $\geq 30 \%$.

INTERMACS profile, LV end-diastolic diameter, LVEF, MR grade, SVR procedure, concomitant $\mathrm{CABG}$, and concomitant mitral valve procedures. Because data for some variables were missing for some patients, the final sample used in the multivariate analysis consisted of 570 patients, 113 of whom died.

Four independent predictors were identified in the final multivariate Cox model: age, INTERMACS profile, LVEF, and MR grade (Table 4). Harrell's C-index of the model was 0.690. Figure E1 shows Kaplan-Meier survival curves for each predictor.

TABLE 4. Multivariate Cox proportional hazards analysis and scoring system

\begin{tabular}{lcccc}
\hline & & \multicolumn{3}{c}{$\boldsymbol{\beta}$ regression } \\
& $\boldsymbol{P}$ value & HR $(\mathbf{9 5} \% \mathbf{C I})$ & $\begin{array}{c} \\
\text { coefficient }\end{array}$ & Points \\
\hline Age, y & .001 & & & \\
$\quad<65$ & & 1 & & 0 \\
$\quad$ 65 & & $1.91(1.29-2.85)$ & 0.649 & 2 \\
INTERMACS profile & $<.001$ & & & \\
$\quad$ Level 1 & & $4.54(2.19-9.43)$ & 1.513 & 4 \\
Level 2 & & $4.16(1.79-9.67)$ & 1.425 & 3 \\
Level 3 & $2.71(1.54-4.76)$ & 0.995 & 2 \\
Level 4 & $1.53(0.90-2.60)$ & 0.425 & 1 \\
Level $\geq 5$ & & 1 & & 0 \\
LVEF, \% & .007 & & \\
$<20$ & & $3.63(1.49-8.82)$ & 1.289 & 3 \\
$20-40$ & & $2.26(0.97-5.27)$ & 0.816 & 2 \\
$\geq 40$ & & 1 & & 0 \\
MR & & & \\
$\leq 1+$ & & 1 & & 0 \\
$2+$ & & $2.09(1.25-3.50)$ & 0.738 & 2 \\
$3+$ & & $2.08(1.20-3.62)$ & 0.734 & 2 \\
$4+$ & $5.09(2.91-8.92)$ & 1.628 & 4 \\
\hline
\end{tabular}

CI, confidence interval; $H R$, hazard ratio; INTERMACS, Interagency Registry for Mechanically Assisted Circulatory Support; $L V E F$, left ventricular ejection fraction; $M R$, mitral regurgitation.

\section{Development of Risk Categories for Postoperative Mortality}

Each independent predictor of mortality was assigned a weighted score in points as shown in Table 4, and a risk score was calculated for each patient by summing the scores for the predictors. As a result, the risk score ranged from 0 to 12. Then 3 risk groups were developed according to the risk scores: low risk (0-4 points), intermediate risk (5-6 points), and high risk (7-12 points). The 30-day mortality rates were $0.3 \%, 0.7 \%$, and $5 \%$ in the low-risk, intermediate-risk, and high-risk groups, respectively $(P=.004)$. Hospital mortality percentages were $2 \%, 4 \%$, and $22 \%$ for these groups, respectively $(P<.001)$.

Figure 1 shows Kaplan-Meier curves for all-cause survival and readmission-free survival. Both survivals were significantly different among the 3 different risk groups $(P<.001$ for each). The 3-year all-cause survivals were $93 \%, 81 \%$, and $44 \%$ in the low-risk, intermediate-risk, and high-risk groups, respectively. The 3-year readmission-free survival rates were $78 \%, 65 \%$, and

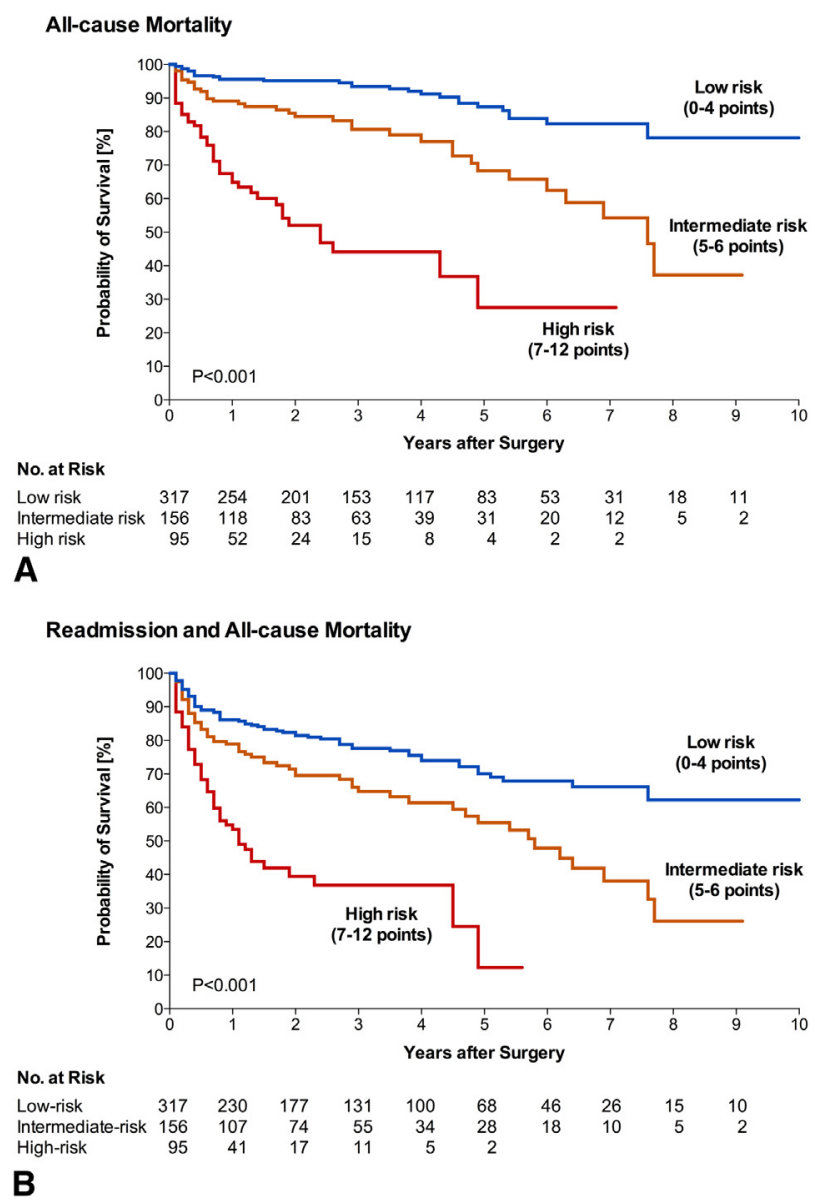

FIGURE 1. Comparisons of Kaplan-Meier survival curves of each risk group according to all-cause mortality (A) and readmission-free survival (B). 
$37 \%$ for the low-risk, intermediate-risk, and high-risk groups, respectively.

NYHA functional classes at different time points were compared among 3 risk groups (Figure E2). Those in the high-risk group presented with a significantly worse NYHA functional class than the others at every time point $(P<.001$ for each). Approximately $90 \%$ of the low-risk patients and $80 \%$ of the intermediate-risk patients had NYHA functional class of II or less at the latest follow-up.

\section{DISCUSSION}

In this study, we identified 4 independent predictors of mortality after SVR for ischemic heart disease: age, INTERMACS profile, LVEF, and MR grade. We developed a prognostic model by calculating weighted risk scores assigned to those predictors. Then 3 risk categories were developed to predict the prognosis according to the risk scores.

Several treatment options can be selected for ischemic heart failure depending on the patient's condition: medication, revascularization, SVR, VAD, and heart transplantation. Because medication alone ${ }^{16}$ or CABG alone ${ }^{17}$ was not associated with satisfactory results in those with severe LV dilatation, acute reverse remodeling by SVR was expected to benefit such patients by reducing $\mathrm{LV}$ volume ${ }^{18}$ and restoring LV shape. ${ }^{19}$ Although a retrospective study with a relatively small sample size showed favorable results for $\mathrm{SVR},{ }^{20}$ a large-scale trial (STICH) found there was no beneficial effect on survival in SVR plus CABG compared with CABG alone. ${ }^{4}$ However, the validity of the STICH results is controversial. ${ }^{5,21}$ STICH seemed to enroll a CABGpreferable population, considering the reported risk factors related to CABG alone, such as an extensively dilated LV and increased number of nonviable segments, ${ }^{22}$ as well as severe LV systolic dysfunction. ${ }^{3}$ CABG alone or SVR plus $C A B G$ may be appropriate for different populations with a small overlap between them. Therefore, they cannot be compared directly. Such a comparison, if the conditions are matched as in the STICH trial, can exclude a number of patients who are eligible for each procedure. Thus, it may result in an inappropriate conclusion that does not reflect the real world. Indeed, favorable results of SVR for those excluded from STICH were reported. ${ }^{23,24}$

However, despite the criticism, that first large-scale trial had enough power to make physicians and surgeons hesitate to select SVR. Although the efficacy of SVR was denied for patients without severe deterioration, the application of SVR for more severe cases also has been considered negatively. Instead, VAD therapy has become spotlighted in this field. VAD has become the more common treatment for severe heart failure, with progressive improvement of survival. ${ }^{6}$ It has advantages in terms of full functional recovery of systemic circulation, although there are unresolved complications, such as stroke, hemorrhage, and device failure. ${ }^{7}$ The cost also has been a problem in VAD therapy. ${ }^{8}$ SVR does not increase the risk of such complications, although it can achieve partial functional recovery of the heart because it uses the patient's own diseased myocardium. Therefore, it is natural that all patients cannot benefit sufficiently from SVR, although it is more cost-effective if performed for appropriately selected patients. ${ }^{25}$

Thus, a comprehensive approach for ischemic heart failure should be developed, including medication, catheter interventions, CABG, SVR, VAD, and heart transplantation. However, the conditions of the patients who are eligible for them may be different. Thus, studies considering the strata of different risk levels for each therapeutic option may be required for more practical comparisons among them and to find the optimal one for each patient. For this purpose, risk stratification for SVR would be a meaningful process to identify the responders to this procedure. We therefore conducted this multicenter study to establish a prognostic model to predict mortality after SVR. We believe our results will contribute to the practical decision-making process in the treatment of those with ischemic heart failure.

\section{INTERMACS Profile}

An advanced NYHA functional class was reported to be an independent predictor of adverse outcomes after SVR. ${ }^{1,2,26}$ In our previous study, NYHA functional class IV was also proved to be one of the strongest predictors of mortality (Y.M and S.W., unpublished data, October 2010). In clinical practice, however, NYHA functional class IV is not always associated with adverse outcomes. Williams and colleauges ${ }^{27}$ reported that NYHA functional class IV was not a significant predictor of mortality. Inotropic dependence is a condition included in NYHA functional class IV and may be a stronger predictor of mortality. SVR for those with a maximum dose of inotropes for cardiogenic shock was associated with high mortality. ${ }^{28}$ In contrast, there was a report that concluded that inotrope use was not a predictor of mortality after SVR for end-stage ischemic cardiomyopathy. ${ }^{29}$ These various results indicate that severe heart failure is a complicated and relatively broad-spectrum condition.

The status of severe heart failure was recently categorized in the INTERMACS profile for VAD therapy. ${ }^{11}$ It is a detailed classification in terms of grading severe heart failure considering inotropic support, organ failure, and cardiogenic shock. As far as we know, no study has evaluated the outcomes of SVR using the INTERMACS profile. We selected the INTERMACS profile as an integrated variable including NYHA functional class, inotropic dependence, hypotension, and renal failure. Moreover, analysis including the INTERMACS profile can make it possible to compare the results and indications for SVR with those of VAD therapy. The indication for SVR should be 
considered as one treatment option in the comprehensive treatment strategy for severe heart failure.

\section{Left Ventricular Size}

There is a contradiction about the indication for SVR in that an extremely dilated $\mathrm{LV}$ is a risk for SVR, ${ }^{1}$ although a dilated LV is an indication for the procedure. ${ }^{20} \mathrm{~A}$ recent subanalysis of the STICH trial concluded that SVR was worse for those with a large $\mathrm{LV} .{ }^{30}$ However, LV size is a variable that has great potential for confounding (eg, the severity of heart failure, MR grade, and LVEF), although most previous studies did not conduct a multivariate analysis of survival time to assess the contribution of baseline LV size to postoperative mortality. ${ }^{1,2}$ In contrast, recent studies focused on the postoperative $\mathrm{LV}$ volume $\left(<60-70 \mathrm{~mL} / \mathrm{m}^{2}\right)$, with sufficient volume reduction as an important predictor of adverse outcomes. ${ }^{26,31}$ However, such studies can exclude those whose condition is too severely deteriorated to undergo postoperative LV assessment studies. Of course, in terms of the quality of SVR, sufficient volume reduction and postoperative LV volume may be important benchmarks. If the concern is who is eligible for SVR, however, those in a severely deteriorated condition should not be excluded from the analysis. Therefore, we assessed only the preoperative value in terms of LV size using a multivariate Cox proportional hazards model with a relatively large sample size. As a result, preoperative LV diameter itself was not identified as a predictor of mortality after SVR. It was also true that LV volume (LVESVI) did not predict the mortality in the multivariate analysis including this variable ( $n=406$, data not shown). Therefore, our results suggested that the patient's condition (heart failure status) and MR severity were more important predictors than LV size. Even for patients with an extremely large LV, SVR can be indicated if heart failure is well controlled and MR is not severe.

\section{Mitral Regurgitation and Mitral Procedures}

In this study, preoperative MR of 4+ was identified as the strongest predictor of mortality, although all of the patients with this condition underwent mitral valve surgery. This was consistent with previous reports that preoperative MR $3+$ or greater predicted mortality in those who underwent SVR with mitral valve procedures. $^{29,32}$ The STICH trial recently suggested that additional mitral valve repair for moderate to severe ischemic MR might improve survival compared with CABG alone or medical treatment alone. ${ }^{33}$ In this study, however, a concomitant mitral valve procedure was not identified as a predictor of survival. O'Neill and colleagues ${ }^{34}$ reported the outcomes of 220 consecutive patients who underwent SVR. Mitral valve surgery was performed for $49 \%$ of them but was not proved to affect survival. It was difficult to assess the efficacy of a concomitant mitral valve procedure because this was an observational study and all of the patients with significant MR underwent the mitral valve procedure. Further study will be required to elucidate the efficacy of mitral procedures.

\section{Surgical Ventricular Reconstruction Procedures}

The appropriate selection of SVR procedures also may be important. Suma and colleagues ${ }^{35}$ reported that site selection of the LV incision according to the location of the scar lesion resulted in improvement of the survival after SVR for nonischemic dilated cardiomyopathy. Various SVR procedures were performed in our cohort, but the differences of the procedures did not affect the outcomes. Although the surgeons in each participating hospital selected SVR procedures on the basis of their preferences, they agreed in considering the regional myocardial viability in selecting the location of the LV incision. Thus, the difference of the procedures (eg, patch use and shape) may not be the predominant issue if the location of the LV incision is appropriately selected. It is considered that $30 \%$ or more reduction of LVESVI is required for an acceptable SVR procedure. ${ }^{5}$ In our cohort, LVESVI reduction of $30 \%$ or more was achieved in $44 \%, 55 \%$, and $69 \%$ of those with baseline LVESVI $60 \mathrm{~mL} / \mathrm{m}^{2}$ or less, 60 to $90 \mathrm{~mL} / \mathrm{m}^{2}$, and greater than $90 \mathrm{~mL} / \mathrm{m}^{2}$, respectively; these rates were higher than those for the STICH trial $(26 \%, 36 \%$, and $45 \%$, respectively). ${ }^{31}$ However, changes in LVEF were comparable.

\section{Study Limitations}

First, the number of procedures performed in each participating hospital was relatively small. However, the results were similar among the participating hospitals (log-rank $P=.11$ ). Second, the relatively short length of the follow-up period could reduce the statistical power of our prognostic model. Third, some variables that may be important (eg, diastolic function) could not be entered in the multivariate analysis because of missing values. Fourth, because only half of the patients had paired data for LV volume from the same modality, it could not be evaluated sufficiently whether SVR in our cohort was performed adequately. Fifth, we did not evaluate the generalizability of our prognostic model using an external validation set. Finally, this is a retrospective and noncomparative study. Although we conducted risk prediction analysis regarding SVR, this scoring system itself cannot indicate the benefit of SVR compared with other treatments (eg, CABG alone, medication, and VAD). Thus, a prospective study that compares different treatment sets considering the risk stratification for each treatment and examines our prognostic model is required.

\section{CONCLUSIONS}

We developed a prognostic model to predict mortality after SVR for those with ischemic heart failure. It can be 
useful in clinical practice to consider the indication for SVR in a comprehensive treatment strategy including medication, catheter interventions, CABG, SVR, VAD, and heart transplantation. Moreover, risk stratification of SVR will contribute to future studies comparing it with other treatment options.

We used data from the Japanese Adult Cardiovascular Surgery Database in selecting participating hospitals. The authors thank Noboru Motomura, $\mathrm{PhD}$, and Hiroaki Miyata, $\mathrm{PhD}$, for planning the study, and Koji Oba, $\mathrm{PhD}$, for statistical help.

\section{References}

1. Athanasuleas CL, Buckberg GD, Stanley AW, Siler W, Dor V, DiDonato M, et al. Surgical ventricular restoration: the RESTORE Group experience. Heart Fail Rev. 2004;9:287-97.

2. Menicanti L, Castelvecchio S, Ranucci M, Frigiola A, Santambrogio C, de Vincentiis C, et al. Surgical therapy for ischemic heart failure: single-center experience with surgical anterior ventricular restoration. J Thorac Cardiovasc Surg. 2007;134:433-41.

3. Appoo J, Norris C, Merali S, Graham MM, Koshal A, Knudtson ML, et al. Longterm outcome of isolated coronary artery bypass surgery in patients with severe left ventricular dysfunction. Circulation. 2004;110:II13-7.

4. Jones RH, Velazquez EJ, Michler RE, Sopko G, Oh JK, O'Connor CM, et al. Coronary bypass surgery with or without surgical ventricular reconstruction. $N$ Engl J Med. 2009;360:1705-17.

5. Buckberg GD, Athanasuleas CL. The STICH trial: misguided conclusions. J Thorac Cardiovasc Surg. 2009;138:1060-4.e2.

6. Kirklin JK, Naftel DC, Kormos RL, Stevenson LW, Pagani FD, Miller MA, et al. The Fourth INTERMACS Annual Report: 4,000 implants and counting. J Heart Lung Transplant. 2012;31:117-26.

7. Yuan N, Arnaoutakis GJ, George TJ, Allen JG, Ju DG, Schaffer JM, et al. The spectrum of complications following left ventricular assist device placement. J Card Surg. 2012;27:630-8.

8. Mulloy DP, Bhamidipati CM, Stone ML, Ailawadi G, Kron IL, Kern JA. Orthotopic heart transplant versus left ventricular assist device: a national comparison of cost and survival. J Thorac Cardiovasc Surg. 2013;145:566-74.

9. Zoghbi WA, Enriquez-Sarano M, Foster E, Grayburn PA, Kraft CD, Levine RA, et al. Recommendations for evaluation of the severity of native valvular regurgitation with two-dimensional and Doppler echocardiography. J Am Soc Echocardiogr. 2003;16:777-802.

10. Harrell FE Jr, Lee KL, Mark DB. Multivariable prognostic models: issues in developing models, evaluating assumptions and adequacy, and measuring and reducing errors. Stat Med. 1996;15:361-87.

11. Stevenson LW, Pagani FD, Young JB, Jessup M, Miller L, Kormos RL, et al. INTERMACS profiles of advanced heart failure: the current picture. $J$ Heart Lung Transplant. 2009;28:535-41.

12. Dor V, Sabatier M, Di Donato M, Montiglio F, Toso A, Maioli M. Efficacy of endoventricular patch plasty in large postinfarction akinetic scar and severe left ventricular dysfunction: comparison with a series of large dyskinetic scars. J Thorac Cardiovasc Surg. 1998;116:50-9.

13. Suma H. Partial left ventriculectomy. Circ J. 2009;73(Suppl A):A19-22.

14. Suma H, Isomura T, Horii T, Nomura F. Septal anterior ventricular exclusion procedure for idiopathic dilated cardiomyopathy. Ann Thorac Surg. 2006;82: 1344-8.

15. Matsui Y, Fukada Y, Suto Y, Yamauchi H, Luo B, Miyama M, et al. Overlapping cardiac volume reduction operation. J Thorac Cardiovasc Surg. 2002;124:395-7.

16. White HD, Norris RM, Brown MA, Brandt PW, Whitlock RM, Wild CJ. Left ventricular end-systolic volume as the major determinant of survival after recovery from myocardial infarction. Circulation. 1987;76:44-51.
17. Yamaguchi A, Ino T, Adachi H, Murata S, Kamio H, Okada M, et al. Left ventricular volume predicts postoperative course in patients with ischemic cardiomyopathy. Ann Thorac Surg. 1998;65:434-8.

18. ten Brinke EA, Klautz RJ, Tulner SA, Verwey HF, Bax JJ, Schalij MJ, et al. Longterm effects of surgical ventricular restoration with additional restrictive mitral annuloplasty and/or coronary artery bypass grafting on left ventricular function: six-month follow-up by pressure-volume loops. J Thorac Cardiovasc Surg. 2010; 140:1338-44.

19. Calafiore AM, Iaco AL, Amata D, Castello C, Varone E, Falconieri F, et al. Left ventricular surgical restoration for anteroseptal scars: volume versus shape. J Thorac Cardiovasc Surg. 2010;139:1123-30.

20. Yamaguchi A, Adachi H, Kawahito K, Murata S, Ino T. Left ventricular reconstruction benefits patients with dilated ischemic cardiomyopathy. Ann Thorac Surg. 2005;79:456-61.

21. Ghali JK. Surgical ventricular reconstruction. N Engl J Med. 2009;361:529. author reply 31-2.

22. Bax JJ, Schinkel AF, Boersma E, Elhendy A, Rizzello V, Maat A, et al. Extensive left ventricular remodeling does not allow viable myocardium to improve in left ventricular ejection fraction after revascularization and is associated with worse long-term prognosis. Circulation. 2004;110:II18-22.

23. Goh S, Prior D, Newcomb A, McLellan A, Mack J, Callaghan S, et al. Surgical ventricular restoration procedure: single-center comparison of Surgical Treatment of Ischemic Heart Failure (STICH) versus non-STICH patients. Ann Thorac Surg. 2013;95:506-12.

24. Dor V, Civaia F, Alexandrescu C, Sabatier M, Montiglio F. Favorable effects of left ventricular reconstruction in patients excluded from the Surgical Treatments for Ischemic Heart Failure (STICH) trial. J Thorac Cardiovasc Surg. 2011;141: 905-16. 16.e1-4.

25. Williams JA, Weiss ES, Patel ND, Nwakanma LU, Reeb BE, Conte JV. Surgical ventricular restoration versus cardiac transplantation: a comparison of cost, outcomes, and survival. J Card Fail. 2008;14:547-54.

26. Witkowski TG, ten Brinke EA, Delgado V, Ng AC, Bertini M, Marsan NA, et al. Surgical ventricular restoration for patients with ischemic heart failure: determinants of two-year survival. Ann Thorac Surg. 2011;91:491-8.

27. Williams JA, Weiss ES, Patel ND, Nwakanma LU, Conte JV. Outcomes following surgical ventricular restoration for patients with clinically advanced congestive heart failure (New York Heart Association Class IV). J Card Fail. 2007;13:431-6.

28. Takeda K, Matsumiya G, Matsue H, Sakaki M, Sakaguchi T, Fujita T, et al. Left ventricular reconstructive surgery in ischemic dilated cardiomyopathy complicated with cardiogenic shock. Ann Thorac Surg. 2008;85:1339-43.

29. Suma H, Tanabe H, Uejima T, Isomura T, Horii T. Surgical ventricular restoration combined with mitral valve procedure for endstage ischemic cardiomyopathy. Eur J Cardiothorac Surg. 2009;36:280-5.

30. Oh JK, Velazquez EJ, Menicanti L, Pohost GM, Bonow RO, Lin G, et al. Influence of baseline left ventricular function on the clinical outcome of surgical ventricular reconstruction in patients with ischaemic cardiomyopathy. Eur Heart J. 2013;34:39-47.

31. Michler RE, Rouleau JL, Al-Khalidi HR, Bonow RO, Pellikka PA, Pohost GM, et al. Insights from the STICH trial: change in left ventricular size after coronary artery bypass grafting with and without surgical ventricular reconstruction. J Thorac Cardiovasc Surg. 2012 Oct 27 [Epub ahead of print].

32. Sartipy U, Albage A, Lindblom D. Risk factors for mortality and hospital readmission after surgical ventricular restoration. Eur J Cardiothorac Surg. 2006;30:762-9.

33. Deja MA, Grayburn PA, Sun B, Rao V, She L, Krejca M, et al. Influence of mitral regurgitation repair on survival in the Surgical Treatment for Ischemic Heart Failure trial. Circulation. 2012;125:2639-48.

34. O'Neill JO, Starling RC, McCarthy PM, Albert NM, Lytle BW, Navia J, et al. The impact of left ventricular reconstruction on survival in patients with ischemic cardiomyopathy. Eur J Cardiothorac Surg. 2006;30:753-9.

35. Suma H, Horii T, Isomura T, Buckberg G, Group R. A new concept of ventricular restoration for nonischemic dilated cardiomyopathy. Eur J Cardiothorac Surg. 2006;29(Suppl 1):S207-12. 


\section{INTERMACS profile}

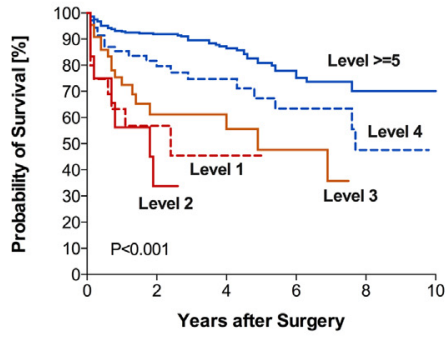

No. at Risk

$$
\begin{aligned}
& \text { Level } 1 \\
& \text { Level } 2 \\
& \text { Level } 3
\end{aligned}
$$$$
\begin{aligned}
& \text { Level } 3 \\
& \text { Level } 4 \\
& \text { Level }>=5
\end{aligned}
$$

A

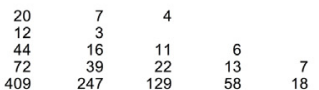

\section{Mitral regurgitation}

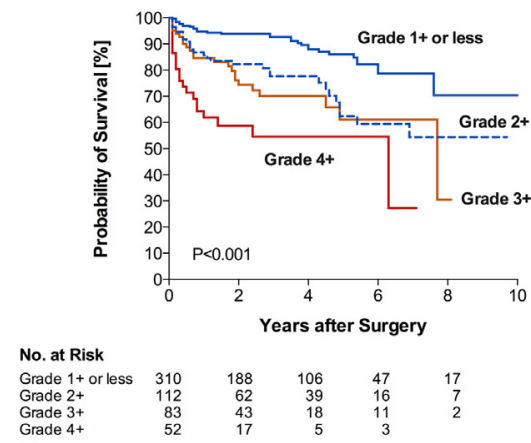

C

\section{LV ejection fraction}

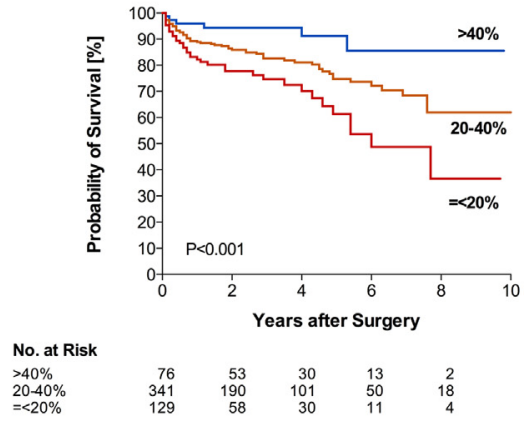

B

Age

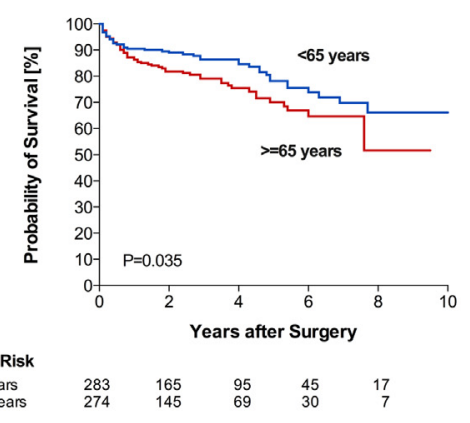

D

FIGURE E1. Comparisons of Kaplan-Meier survival curves in terms of INTERMACS profiles (A), LVEF (B), MR (C), and age (D). INTERMACS, Interagency Registry for Mechanically Assisted Circulatory Support; $L V$, left ventricle.

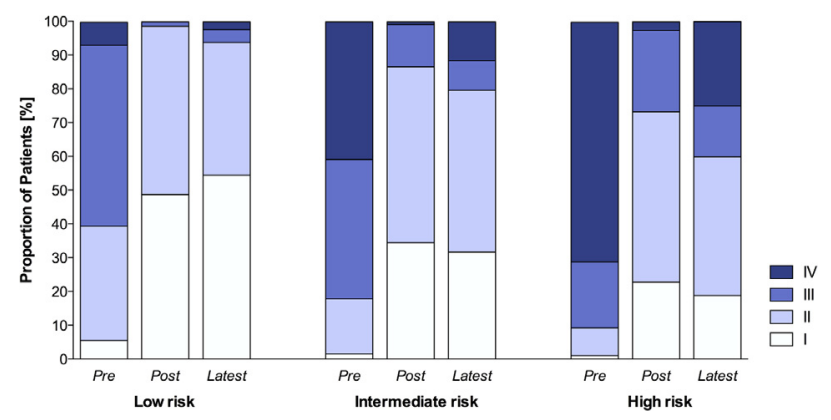

FIGURE E2. Comparisons of NYHA functional classes among risk groups at different time points. 
TABLE E1. Assessment of potential predictors of mortality using univariate Cox proportional hazards model

\begin{tabular}{|c|c|c|c|}
\hline & $\mathbf{N}$ & $P$ value & $\begin{array}{c}\text { Hazard } \\
\text { ratio }(95 \% \mathrm{CI})\end{array}$ \\
\hline Age, y & & .06 & \\
\hline$<65$ & 306 & & 1 \\
\hline$\geq 65$ & 290 & & $1.40(0.98-2.01)$ \\
\hline Sex & & .65 & \\
\hline Female & 224 & & 1 \\
\hline Male & 372 & & $0.92(0.64-1.33)$ \\
\hline NYHA functional class & & $<.001$ & \\
\hline I & 22 & & 1 \\
\hline II & 150 & & $1.51(0.36-6.44)$ \\
\hline III & 267 & & $1.61(0.39-6.66)$ \\
\hline IV & 156 & & $4.46(1.09-18.27)$ \\
\hline Inotropic support & & $<.001$ & \\
\hline No & 513 & & 1 \\
\hline Yes & 79 & & $3.79(2.56-5.63)$ \\
\hline INTERMACS profile & & $<.001$ & \\
\hline Level 1 & 21 & & $5.19(2.48-10.89)$ \\
\hline Level 2 & 12 & & $7.74(3.30-18.17)$ \\
\hline Level 3 & 46 & & $3.82(2.09-6.99)$ \\
\hline Level 4 & 77 & & $1.99(1.12-3.56)$ \\
\hline Level 5-6 & 267 & & $1.11(0.67-1.84)$ \\
\hline Level $\geq 7$ & 172 & & 1 \\
\hline LV shape* & & .07 & \\
\hline Aneurysmal & 184 & & $0.68(0.45-1.03)$ \\
\hline Nonaneurysmal & 379 & & 1 \\
\hline LV end-diastolic diameter, $\mathrm{mm}$ & & $<.001$ & \\
\hline$\leq 55$ & 142 & & 1 \\
\hline $55-60$ & 118 & & $1.56(0.78-3.13)$ \\
\hline $60-70$ & 206 & & $2.28(1.26-4.10)$ \\
\hline$>70$ & 108 & & $4.08(2.25-7.40)$ \\
\hline LVESVI, $\mathrm{mL} / \mathrm{min}^{2}, *$ & & .003 & \\
\hline$\leq 80$ & 119 & & 1 \\
\hline $80-100$ & 93 & & $2.12(0.88-5.12)$ \\
\hline $100-140$ & 117 & & $3.36(1.53-7.40)$ \\
\hline$>140$ & 89 & & $4.13(1.86-9.16)$ \\
\hline LVEF, \% & & $<.001$ & \\
\hline$\leq 20$ & 135 & & $4.60(1.97-11.0)$ \\
\hline $20-40$ & 354 & & $2.66(1.16-6.13)$ \\
\hline$>40$ & 80 & & 1 \\
\hline MR & & $<.001$ & \\
\hline None & 110 & & 1 \\
\hline $1+$ & 207 & & $1.02(0.51-2.04)$ \\
\hline $2+$ & 116 & & $2.52(1.30-4.92)$ \\
\hline $3+$ & 84 & & $3.02(1.51-6.04)$ \\
\hline $4+$ & 53 & & $6.36(3.13-12.91)$ \\
\hline SVR procedure (patch use) & & .68 & \\
\hline No patch & 154 & & 1 \\
\hline Patch & 442 & & $1.10(0.72-1.68)$ \\
\hline SVR procedure (type) & & .39 & \\
\hline EVCPP & 258 & & 1 \\
\hline PLV & 14 & & $0.69(0.10-5.00)$ \\
\hline SAVE & 184 & & $1.32(0.87-2.00)$ \\
\hline Overlapping & 62 & & $1.61(0.92-2.82)$ \\
\hline Linear & 78 & & $0.96(0.50-1.85)$ \\
\hline
\end{tabular}

$7.74(3.30-18.17)$

$3.82(2.09-6.99)$

$1.99(1.12-3.56)$
TABLE E1. Continued

\begin{tabular}{|c|c|c|c|}
\hline & $\mathbf{N}$ & $P$ value & $\begin{array}{c}\text { Hazard } \\
\text { ratio }(95 \% \mathrm{CI})\end{array}$ \\
\hline CABG & & .001 & \\
\hline Not performed & 83 & & 1 \\
\hline Performed & 513 & & $0.49(0.32-0.76)$ \\
\hline Mitral valve procedure & & $<.001$ & \\
\hline Not performed & 345 & & 1 \\
\hline Performed & 251 & & $2.66(1.85-3.83)$ \\
\hline \multicolumn{4}{|c|}{$\begin{array}{l}C A B G \text {, Coronary artery bypass grafting; } C I \text {, confidence interval; } E V C P P \text {, endoven- } \\
\text { tricular circular patch plasty; } I N T E R M A C S \text {, Interagency Registry for Mechanically } \\
\text { Assisted Circulatory Support; } L V \text {, left ventricle; } L V E F \text {, left ventricular ejection frac- } \\
\text { tion; } L V E S V I \text {, left ventricular end-systolic volume index; } M R \text {, mitral regurgitation; } \\
N Y H A \text {, New York Heart Association; } P L V \text {, partial left ventriculectomy; SAVE, septal } \\
\text { anterior ventricular exclusion; } S V R \text {, surgical ventricular reconstruction. *Proportion } \\
\text { of those with missing values } \geq 5 \% \text {. }\end{array}$} \\
\hline
\end{tabular}

with missing values $\geq 5 \%$. 